\title{
The Association of Clinical Characteristics and Lifestyle Habits with Poor Glycemic Control in Patients with Type 2 Diabetes Mellitus
}

\author{
Marijan Marjanović, Vedran Đido, Valerija Bralić Lang, Željko Martinović, and Amer Ovčina
}

\section{ABSTRACT}

Background: The goal of this paper is to explore clinical characteristics and lifestyle habits in patients with type 2 diabetes mellitus and their association with poor glycemic control.

Material and Methods: Total of 541 subjects of over 40 years of age with type 2 diabetes mellitus of both genders were included in the study. Anthropometric measurement, glucose level in plasma, HbA1c, triglycerides, AST, ALT, creatinine and eGFR were collected at the time of study entry and patients were asked to fill out the questionnaire on lifestyle habits.

Results: Patients with elevated triglyceride and LDL cholesterol levels, alcohol consumers and smokers were more likely to have poorly controlled glycaemia.

Conclusions: Our study showed a significant impact of patient characteristics to poor glycemic control. Physician activities to reduce cholesterol, triglyceride levels and improve lifestyle habits in patients with type 2 diabetes mellitus will result in better glycemic control.

Keywords: General physicians, Clinical characteristics, Lifestyle habits, Primary Health Care, Diabetes mellitus type 2.

Published Online: January 22, 2021

ISSN: 2593-8339

DOI: $10.24018 /$ ejmed.2021.3.1.676

Marijan Marjanović

Faculty of Health Care, University

„Vitez" in Vitez, Bosnia and

Herzegovina.

Vedran Đido*

Faculty of Health Studies, University of Sarajevo, Bosnia and Herzegovina.

(e-mail: vedran.djido@fzs.unsa.ba)

Valerija Bralić Lang

Private Family Physician Office affiliated

to University of Zagreb, School of Medicine, Zagreb, Croatia.

Željko Martinović

Croatian Hospital "Dr. Fra Mato Nikolić", Nova Bila, Bosnia and Herzegovina.

Amer Ovčina

Faculty of Health Studies, University of Sarajevo, Bosnia and Herzegovina.

*Corresponding Author

\section{INTRODUCTION}

Type 2 diabetes mellitus has reached epidemic proportions globally because the eating habits have changed [1]. Generally, type 2 diabetes mellitus develops after age 40 , and aging itself can increase susceptibility to glucose intolerance and diabetes, as well as physical inactivity and obesity. According to the International Diabetes Federation (IDF), there are 463 million people worldwide living with diabetes in 2019. If this trend continues, 693 million people (age 18-99) will have diabetes by 2045 [2].

The causes for the rising epidemic of type 2 diabetes mellitus are primarily obesity, sedentary lifestyle, increased consumption of unhealthy food such as red and processed meat, refined grains, and sugary beverages [3]. Sociodemographic factors associated with development of type 2 diabetes mellitus are: age, race, ethnicity, male sex and socioeconomic status [6]. Population in Bosnia and Herzegovina (BH) is ethnically divided into Bosniaks, mostly Muslims and Serbs and Croats who are mostly Christians. Despite the diverse religions in this country, there was a lack of research examining the possible relationship of religion and religiosity in T2D patients. Research in Malaysia has shown that Christians have better glycemic control than Muslims [4].

Lack of patient education increases the risk of diabetes for $41 \%$, working at low-paid jobs for $31 \%$ and bad socioeconomic status for $40 \%$, while a change of lifestyle and diet can be effective in prevention of type 2 diabetes mellitus [5].

It is estimated that one-third of newly diagnosed diabetes patients is due to population growth and ageing, $28 \%$ due to the rise in prevalence according to age, and $32 \%$ due to interaction of these two factors [6].

In $\mathrm{BH}$ the exact number of diabetic patients is unknown due to the lack of national diabetes register, but according to the IDF, BH is ranked third in Europe with diabetes prevalence at $11,7 \%$ in adults (ages 20-79) [2]. The available data for part of $\mathrm{BH}$, more precisely for the Federation of $\mathrm{BH}$ show rise in mortality from diabetes for $5.9 \%$ in 2016. and it is twice higher than in surrounding countries [7].

Percentage of everyday smokers in $\mathrm{BH}$ is $44,1 \%$, with $31,6 \%$ and $56,3 \%$ for female and male. Percentage of physical activity is $24,6 \%$, with $20,3 \%$ and $28,7 \%$ for female and male respectively, while percentage of triglyceride equal or above $1,7 \mathrm{mmol} / \mathrm{L}$ is $21.2 \%$. Percentage of cholesterol equal or above $5 \mathrm{mmol} / \mathrm{L}$ is $44.4 \%$ [8]. 
There is general trend of increased overall mortality rate, rates of malignant and cardiovascular diseases, as well as unhealthy lifestyles in BH. Very often it is explained by the consequences of the latest war, as well as unhealthy lifestyles [9].

Among other things, glycemic control depends on food, physical activity, medication, other diseases, alcohol, stress, hormones and the individual treatment goals should depend on these factors [2], [10].

The goal of this paper is to explore clinical characteristics and lifestyle habits in patients with type 2 diabetes mellitus and their association with poor glycemic control in general/family medicine clinics in Central Bosnia Canton.

\section{PATIENTS AND METHODS}

A cross-sectional study was conducted in general medical centers in Central Bosnia Canton, Bosnia and Herzegovina, from August 2018 to February 2019. The study included subjects of both sexes who were older than 40, had type 2 diabetes mellitus diagnosed at least 3 years prior to the study, and they visited their doctor at the time the study was conducted and agreed to participate. The subjects who could not understand questions without help and whose life expectancy was less than a year, were excluded from the study. Patients were informed about the purpose of the study and told that the study participation was anonymous and voluntary. The total number of subjects was 541 .

Cholesterol, triglyceride, AST, ALT, and creatinine levels were collected from patients' medical records and used for the study purposes if performed within past year, otherwise blood tests were conducted, while glucose in plasma and HbA1c were measured at the day of entrance in the study. Patients were asked to fill out the questionnaire on lifestyle habits immediately on the day of study entry. Poorly controlled glycaemia was defined at the HbA1c level, which was higher than $7.5 \%$.

The study was conducted with a questionnaire previously used in the work of Bralić Lang and associates [11].

The lifestyle habits explored with this questionnaire are defined as follows:

1. An unhealthy diet was implied if at least two of the following habits were reported: consumption of animal fat, daily intake of salt-cured meat, milk, and dairy products with more than $3.2 \%$ fat, occasionally or never consuming fruit, always adding extra salt to food

2. Physical inactivity was implied if at least two of the following habits were reported: working at home, traveling to work by public transport or working within a 15 minute walking or cycling distance, easy or very easy job (physical effort), physical activity of less than 30 min a day during leisure time, having received advice by a health care professional to increase physical activity

3. If the answer to any of the questions concerning alcohol intake was affirmative, it was treated as if patient consumed alcohol

4. Smoking: Patients who have been reported smoking were considered at risk.

Patients' 'stress level was measured by a generic questionnaire for assessment of generally perceived psychological stress (the Perceived Stress Scale, PSS).
Patients answered the questions using a Likert scale. By reversing the scores on positive questions $4,5,7$, and 8 a total PSS-10 score was obtained. The stress level was later obtained as a gross score of all 10 responses, with affirmative positive questions recoded. Scores on the PSS range from 0 to 40 with higher scores indicating greater overall stress levels. The total stress score was additionally classified into three categories: 0-13: low level of stress; 1426: medium level of stress; 27-40: high level of stress.

The consent of the Ethics Committee of the Faculty of Medicine, University of Split was obtained for the study in accordance with the Declaration of Helsinki, and written informed consent was obtained from all participants.

\section{A. Statistical Analysis}

The level of statistical significance was set at 5\% $(\mathrm{p}<0.05)$, and all confidence intervals were given at the level of $95 \%$. The normality of the distribution of continuous variables was tested with Kolmogorov-Smirnov test. In cases of statistically significant deviations in distribution of results from the normal distribution, the median and interquartile ranges were used as measures of central tendency and dispersion, and in all other cases the arithmetic mean and standard deviation were used.

Binary logistic regression was used for univariate and multivariate prediction. Gender and age were included in the multivariate prediction as control variables, and from the other variables, those that were associated with the criterion at the level of statistical significance of $p<0.250$ were used. All statistical methods were performed using SPSS for Windows, version 20.0 (SPSS Inc. Chicago, IL, USA).

\section{RESULTS}

We studied lifestyle habits and self-reported stress of 541 patients with T2DM and median age 65. There were 307 (56.7\%) female participants (Table I). Almost all (90.4\%) participants had comorbidities and $85 \%$ of them had some chronic therapy other than oral antidiabetics. More than third $(35.4 \%)$ of them had diabetic complications and less than $10 \%$ of them achieved targeted level of blood pressure advised for T2DM patients. Level of HbA1c ranged from 4.5 to $13.0 \%$, and $208 / 541(38.4 \%)$ of patients had $\mathrm{HbA} 1 \mathrm{c}$ level higher than $7.5 \%$, while $45 / 541(8.3 \%)$ of them had HbA1c level $\geq 9.0 \%$ or higher.

When it comes to lifestyle habits, 232/536 (43.3\%) of patients had unhealthy diet, more than half 296/529 (56.0\%) were physically inactive, almost a fifth $(17.9 \%)$ of them were advised to stop alcohol-consuming and 141/536 (26.3\%) were smokers.

Poorly controlled glycaemia was observed in 196/532 $(36.8 \%)$ patients. Among the studied patients' clinical characteristics, at the univariate level of analysis, statistically significant predictors of poorly controlled glycaemia were LDL cholesterol, triglyceride and eGFR. Therefore, patients with elevated level of LDL cholesterol were more likely to have poor glycemic control as compared to ones with normal levels, patients with elevated triglyceride levels were also more likely to have poor control as compared to ones with normal level. Patients who had moderately or severely reduced eGFR were less likely 
to have poorly controlled glycaemia as compared to patients with its normal level (Table II).

\section{TABLE I: PATIENTS' CHARACTERISTICS}

$\begin{array}{lll}\text { Sex, N (\%) } & & \\ \quad \text { male } & 234 / 541 & (43.3) \\ \quad \text { female } & 307 / 541 & (56.7) \\ \text { Age (years), median (IQR) } & 65 & (60-70) \\ \text { BMI (kg/m2), median (IQR) } & 28.5 & (25.9-32.0) \\ \text { Waist circumference (cm), median (IQR) } & & \\ \quad \text { male } & 95 & (92-102) \\ \quad \text { female } & 95 & (88-103) \\ \text { Cholesterol (mmol/l), median (IQR) } & 5.5 & (4.9-6.3) \\ \text { HDL cholesterol (mmol/l), median (IQR) } & & \\ \quad \text { male } & 1.3 & (1.1-1.6) \\ \quad \text { female } & 1.4 & (1.2-1.8) \\ \text { LDL cholesterol (mmol/l), median (IQR) } & 2.9 & (2.2-3.8) \\ \text { Triglycerides, median (IQR) } & 2.0 & (1.5-2.7) \\ \text { Creatinine (mmol/l), median (IQR) } & 80 & (70-94) \\ \text { eGFR, median (IQR) } & 75.0 & (61.5-88.0) \\ \text { Targeted level of blood pressure for T2DM } & & \\ \text { (< 140/80 mmHg) achieved, n (\%) } & 39 / 539 & (7.2) \\ \text { Other chronic diseases present, n (\%) } & 489 / 541 & (90.4) \\ \text { Chronic therapy other than OAD present, n (\%) } & 460 / 541 & (85.0) \\ \text { Fasting glycemia (mmol/l), median (IQR) } & 7.8 & (7.1-9.5) \\ \text { Postprandial glycemia (mmol/l), median (IQR) } & 9.3 & (8.1-11.5) \\ \text { HbA1c, median (IQR) } & 7.2 & (6.5-8.0) \\ \text { Diabetes complications present, n (\%) } & 191 / 539 & (35.4) \\ \text { Unhealthy diet, n (\%) } & 232 / 536 & (43.3) \\ \text { Advised to increase physical activity, n (\%) } & 296 / 529 & (56.0) \\ \text { Advised to stop alcohol-consuming, n (\%) } & 90 / 502 & (17.9) \\ \text { Current smokers, n (\%) } & 141 / 536 & (26.3) \\ \text { Stress } & & \\ \quad \text { low level (0-13) } & 73 / 536 & (13.6) \\ \quad \text { moderate level (14-26) } & 446 / 536 & (83.2) \\ \quad \text { high level (27-40) } & 17 / 536 & (3.2) \\ \quad & \end{array}$

Patients with unhealthy diet and patients who smoked had statistically greater chance for poorly controlled glycaemia $(\mathrm{p}<0.001)$. On the other hand, physically inactive patients had significantly less chance to have poorly regulated glycaemia than physically active patients $(\mathrm{p}<0.001)$ Stress did not show statistically significant difference $(p=0,238)$, but those patients with moderate and high risk of stress were more likely to have poor glycemic control (Table III).

With control of other variables included in the predictive model, multivariate prediction was used to determine a relation between poorly controlled glycaemia and certain patient characteristics. All variables that in univariate analysis were associated with poorly controlled glycaemia at the level of statistical significance less than $\mathrm{p}=0.25$ were entered in a predictive model. With multivariate prediction it was defined that statistically significant predictors of poorly controlled glycaemia were levels of LDL cholesterol, triglyceride, eGFR and unhealthy diet, physical inactivity, alcohol consumption and smoking. With control of other variables included in a predictive model, patients with increased levels of LDL cholesterol had higher chances for poorly controlled glycaemia as compared to ones with normal levels, patients with elevated triglyceride levels also had better odds for poorly controlled glycaemia. Patients with moderate or severe decrease of eGFR were less likely to have poorly controlled glycaemia as compared to patients with normal level. Chances for poorly controlled glycaemia increased with unhealthy diet, alcohol consumption, smoking, while they were lower in physically inactive patients (Table IV).

TABLE II: POORLY CONTROLLED GLYCAEMIA WITH RESPECT TO THE CLINICAL CHARACTERISTICS OF PATIENTS

\begin{tabular}{|c|c|c|c|c|c|c|c|}
\hline & \multicolumn{2}{|c|}{$\begin{array}{l}\text { Good controlled } \\
\text { glycaemia }<7,5 \%\end{array}$} & \multicolumn{2}{|c|}{$\begin{array}{l}\text { Poorly controlled } \\
\text { glycaemia } \geq 7,5 \%\end{array}$} & \multirow{2}{*}{$\mathrm{OR}_{\mathrm{UV}}$} & \multirow[t]{2}{*}{$(95 \% \mathrm{CI})$} & \multirow[t]{2}{*}{$\mathrm{P}$} \\
\hline & $\mathrm{N}$ & $(\%)$ & $\mathrm{N}$ & $(\%)$ & & & \\
\hline \multicolumn{8}{|l|}{ Cholesterol (mmol/L) (T1) } \\
\hline normal $(<4,5)$ & 55 & $(70,5)$ & 23 & $(29,5)$ & 1 & & \\
\hline increased $(\geq 4,5)$ & 280 & $(61,8)$ & 173 & $(38,2)$ & 1,48 & $(0,88-2,49)$ & 0,143 \\
\hline \multicolumn{8}{|l|}{ HDL cholesterol (mmol/L) } \\
\hline $\operatorname{normal}(\mathrm{m}:>1, \mathrm{f}:>1,2)$ & 238 & $(62,1)$ & 145 & $(37,9)$ & 1 & & \\
\hline decreased $(m: \leq 1, f: \leq 1,2)$ & 96 & $(65,8)$ & 50 & $(34,2)$ & 0,86 & $(0,57-1,28)$ & 0,442 \\
\hline \multicolumn{8}{|l|}{ LDL cholesterol (mmol/L) } \\
\hline normal $(<3,0)$ & 147 & $(51,9)$ & 136 & $(48,1)$ & 1 & & \\
\hline increased $(\geq 3,0)$ & 188 & $(76,1)$ & 59 & $(23,9)$ & 1,48 & $(1,03-1,99)$ & $<0,001$ \\
\hline \multicolumn{8}{|l|}{ Triglycerides (mmol/L) } \\
\hline normal $(<1,7)$ & 136 & $(74,7)$ & 46 & $(25,3)$ & 1 & & \\
\hline increased $(\geq 1,7)$ & 198 & $(56,9)$ & 150 & $(43,1)$ & 2,24 & $(1,51-3,33)$ & $<0,001$ \\
\hline \multicolumn{8}{|l|}{ Creatinine $(\mathrm{mmol} / \mathrm{L})(\mathrm{T} 1)$} \\
\hline $\operatorname{normal}(\mathrm{m}:<115, \mathrm{f}:<107)$ & 302 & $(60,9)$ & 194 & $(39,1)$ & & & \\
\hline elevated (m: $\geq 115, f: \geq 107)$ & 32 & $(100,0)$ & 0 & $(0,0)$ & - & - & \\
\hline \multicolumn{8}{|l|}{ eGFR (ml/min/1,73m2) } \\
\hline normal level $(\leq 90)$ & 67 & $(55,8)$ & 53 & $(44,2)$ & 1 & & \\
\hline slight decrease (60-89) & 175 & $(60,8)$ & 113 & $(39,2)$ & 0,82 & $(0,53-1,26)$ & 0,356 \\
\hline $\begin{array}{l}\text { moderate or severe decrease } \\
(15-59)\end{array}$ & 92 & $(76,7)$ & 28 & $(23,3)$ & 0,39 & $(0,22-0,67)$ & 0,001 \\
\hline \multicolumn{8}{|c|}{$\begin{array}{l}\text { Targeted level of blood pressure for } \\
\text { T2DM }\end{array}$} \\
\hline achieved $(<140 / 80 \mathrm{mmHg})$ & 27 & $(71,1)$ & 11 & $(28,9)$ & 1 & & \\
\hline not achieved & 308 & $(62,6)$ & 184 & $(37,4)$ & 1,47 & $(0,71-3,03)$ & 0,300 \\
\hline
\end{tabular}

Abbreviations: $\mathrm{OR}_{\mathrm{UV}}=$ odds ratio; univariate, binary logistic regression; $95 \% \mathrm{CI}=95 \%$ confidence interval for odds ratio. 
TABLE III: POORLY CONTROLLED GLYCAEMIA WITH RESPECT TO LIFESTYLE HABITS AND STRESS

\begin{tabular}{|c|c|c|c|c|c|c|c|}
\hline & \multicolumn{2}{|c|}{$\begin{array}{l}\text { Good controlled } \\
\text { glycaemia }<7,5 \%\end{array}$} & \multicolumn{2}{|c|}{$\begin{array}{l}\text { Poorly controlled } \\
\text { glycaemia } \geq 7,5 \%\end{array}$} & \multirow[t]{2}{*}{$\mathrm{OR}_{\mathrm{UV}}$} & \multirow[t]{2}{*}{$(95 \% \mathrm{CI})$} & \multirow[t]{2}{*}{$\mathrm{P}$} \\
\hline & $\mathrm{N}$ & $(\%)$ & $\mathrm{N}$ & $(\%)$ & & & \\
\hline \multicolumn{8}{|l|}{ Unhealthy diet } \\
\hline no & 212 & $(71,1)$ & 86 & $(28,9)$ & 1 & & \\
\hline yes & 121 & $(52,8)$ & 108 & $(47,2)$ & 2,20 & $(1,53-3,16)$ & $<0,001$ \\
\hline \multicolumn{8}{|l|}{ Physical inactivity } \\
\hline no & 24 & $(40,7)$ & 35 & $(59,3)$ & 1 & & \\
\hline yes & 307 & $(65,9)$ & 159 & $(34,1)$ & 0,36 & $(0,20-0,62)$ & $<0,001$ \\
\hline \multicolumn{8}{|l|}{$\begin{array}{l}\text { Advised to increase physical } \\
\text { Activity }\end{array}$} \\
\hline no & 143 & $(62,7)$ & 85 & $(37,3)$ & 1 & & \\
\hline yes & 183 & $(62,7)$ & 109 & $(37,3)$ & 1,00 & $(0,70-1,43)$ & 0,991 \\
\hline \multicolumn{8}{|l|}{ Alcohol consumption } \\
\hline no & 315 & $(64,4)$ & 174 & $(35,6)$ & 1 & & \\
\hline yes & 18 & $(52,9)$ & 16 & $(47,1)$ & 1,61 & $(0,80-3,24)$ & 0,182 \\
\hline \multicolumn{8}{|l|}{$\begin{array}{l}\text { Advised to quit alcohol } \\
\text { consumption }\end{array}$} \\
\hline no & 257 & $(63,6)$ & 147 & $(36,4)$ & 1 & & \\
\hline yes & 56 & $(62,9)$ & 33 & $(37,1)$ & 1,03 & $(0,64-1,66)$ & 0,902 \\
\hline \multicolumn{8}{|l|}{ Smoking } \\
\hline no & 270 & $(69,8)$ & 117 & $(30,2)$ & 1 & & \\
\hline yes & 63 & $(45,0)$ & 77 & $(55,0)$ & 2,82 & $(1,90-4,20)$ & $<0,001$ \\
\hline \multicolumn{8}{|l|}{ Stress } \\
\hline low level (0-13) & 50 & $(69,4)$ & 22 & $(30,6)$ & 1 & & \\
\hline moderate/high level (14-40) & 283 & $(62,2)$ & 172 & $(37,8)$ & 1,38 & $(0,80-2,36)$ & 0,238 \\
\hline
\end{tabular}

Abbreviations: $\mathrm{OR}_{\mathrm{UV}}=$ odds ratio; univariate, binary logistic regression; $95 \% \mathrm{CI}=95 \%$ confidence interval for odds ratio.

TABLE IV1. Multivariate PREDiCTION OF POORLy CONTROLled GLYCAEMIA (N=185) VERSUS GOOD CONTROL $(\mathrm{N}=323)$

\begin{tabular}{lccc}
\multicolumn{4}{l}{ GLYCAEMIA $(\mathrm{N}=185)$ VERSUS GOOD CONTROL $(\mathrm{N}=323)$} \\
\hline & $\mathrm{OR}_{\mathrm{MV}}$ & $(95 \% \mathrm{CI})$ & $\mathrm{P}$ \\
\hline Female & 2,26 & $(1,00-5,10)$ & 0,051 \\
Age of the patient & & & \\
$\quad 60-69$ & 1,11 & $(0,50-2,49)$ & 0,797 \\
$\geq 70$ & 2,47 & $(0,85-7,19)$ & 0,098
\end{tabular}

Body mass index

\begin{tabular}{lccc}
$25-29,99 \mathrm{~kg} / \mathrm{m}^{2}$ & 0,68 & $(0,28-1,66)$ & 0,400 \\
$\geq 30 \mathrm{~kg} / \mathrm{m}^{2}$ & 1,20 & $(0,46-3,12)$ & 0,715 \\
Increased waist circumference - IDF & 2,23 & $(0,94-5,31)$ & 0,071 \\
$\mathrm{~m}:>94 \mathrm{~cm}, \mathrm{f}:>80 \mathrm{~cm})$ & & & \\
Elevated cholesterol $(\geq 4,5)$ & 1,27 & $(0,44-3,70)$ & 0,664 \\
Elevated LDL cholesterol $(\geq 3,0)$ & 1,66 & $(1,12-2,55)$ & $<0,001$ \\
Elevated triglycerides $(\geq 1,7)$ & 3,15 & $(1,45-6,82)$ & 0,004 \\
eGFR (ml/min/1,73 m $)$ & & & \\
slight reduction $(60-89)$ & 0,51 & $(0,20-1,29)$ & 0,154 \\
moderate or severe reduction $(15-$ & 0,17 & $(0,05-0,55)$ & 0,003 \\
59) & & & \\
Unhealthy diet & 2,42 & $(1,18-4,95)$ & 0,016 \\
Physical inactivity & 0,11 & $(0,03-035)$ & $<0,001$ \\
Alcohol consumption & 6,44 & $(1,63-25,46)$ & 0,008 \\
Smoking & 4,48 & $(2,12-9,45)$ & $<0,001$ \\
\hline
\end{tabular}

Abbreviations: $\mathrm{OR}_{\mathrm{mv}}=$ odds ratio; multivariate, binary logistic regression; $95 \% \mathrm{CI}=95 \%$ confidence interval for odds ratio

\section{DISCUSSION}

In our study, patients with elevated triglyceride levels, LDL cholesterol, alcohol consumers and smokers were more likely to have poorly controlled glycaemia.

Patients with elevated triglyceride levels were more likely to have poorly controlled glycaemia. It is known that elevated triglyceride levels increase the chance for diabetes and prediabetes, and a recent study of over 20,000 patients with type 2 diabetes mellitus showed that elevated triglyceride levels significantly increase the chance for poor glycemic control, but also that better control of triglyceride levels affects the better glycemic control [12]. On average triglycerides are higher in patients with type 2 diabetes as compared to healthy population [13], and in our study, the triglyceride levels were elevated in $65 \%$ of subjects, while $85 \%$ had elevated cholesterol levels.

About half subjects in our study did not have satisfying LDL cholesterol levels, which is consistent with previous results [14]. In patients with elevated LDL cholesterol levels, chances for poorly controlled glycaemia were significantly higher than in patients with normal level of this lipid. One of the most common parameters for estimating the risk of cardiovascular disease is LDL cholesterol, therefore it is important that it does not exceed $3 \mathrm{mmol} / \mathrm{Lin}$ T2DM patients [15], while decrease in LDL cholesterol by $1 \mathrm{mmol} / \mathrm{L}$ results in lower chance for myocardial infarction and cerebrovascular insult [16].

Every fourth subject in our study stated he smoked, and they were more likely to have poor glycemic control. A similar study in neigbouring Croatia showed $19.4 \%$ prevalence of smokers among patients with type 2 diabetes mellitus [11]. Large meta-analysis that included prospective studies on connection between smoking and risk of type 2 diabetes mellitus, found that both passive and active smoking significantly increase the risk for development of type 2 diabetes [17]. There are several possible pathophysiological mechanisms that explain the impact of smoking on poor glycemic control, mainly that cigarette smoking is associated with insulin resistance [18], and that 
smokers are more likely to have systemic inflammation [19] and increased sympathicus activity [20]. Smoking and smoking cessation definitely affect glycemic control, but their impact depends on duration, number of smoked cigarettes and the time when person quit smoking [21].

By using multivariate prediction, chances for poor glycemic control were higher in patients who consumed alcohol, as compared to those who didn't. Similar study in Croatia found that patients who had received anyone's advice to stop consuming alcohol were significantly associated with HbA1c levels [11]. Alcohol consumption in our study refers to all affirmative answers related to alcohol, including low, moderate, and excessive consumption. It was pointed earlier that low and moderate alcohol consumption is associated with a lower risk of type 2 diabetes mellitus, while excessive alcohol consumption is not associated with this risk. While excessive alcohol consumption is not recommended to anyone, moderate consumption shouldn't be forbidden to T2DM patients and it is recommended to healthy people [22].

Chances for poor glycemic control decreased with eGFR increase. The assumption suggests that patients with higher eGFR levels were healthier and had less chance for diabetes complication.

The risk of cardiovascular diseases increases when eGFR is below $45 \mathrm{ml} / \mathrm{min} / 1.73 \mathrm{~m}^{2}$ [23], i.e., higher eGFR indicates that these are healthier patients who care about their health and therefore have better glucoregulation.

Unhealthy diet was reported in $43.3 \%$ of subjects and they were more likely to have poor glycemic control. Diet significantly affects glycemic control, especially in last few years because dietary habits have changed. It is found that unhealthy diet along with physical inactivity increases the risk of poor glycemic control for up to 7 times [24].

Surprisingly, chances for poorly controlled glycaemia were lower in the case of physically inactive patients. Physical activity in the form of aerobics in T2DM patients leads to a decrease of $\mathrm{HbA} 1 \mathrm{c}$, triglyceride, blood pressure and insulin resistance [25], while physical exercise of 150 minutes per week contributes to better glycemic control [26]. To support this thesis, a large meta-analysis of 12 studies in adults with type 2 diabetes showed positive effect of aerobics on the reduction in HbA1c levels [27]. Since our study included only people over 40 , and almost $80 \%$ of them were over 60 years old, the outcome was that $80 \%$ of respondents did not work or worked at home. This led to the fact that only $59(11.2 \%)$ subjects in our study were physically active, while $466(88.8 \%)$ were not physically active, which is almost identical to the results in Greek PANORAMA study [14]. Physical activity should be advised to everyone, especially T2DM patients, and individualized recommendations should depend on the type of diabetes, age, complications, and profession [28].

Some patients do not want to adhere to a lifestyle change, or treatment change. In the study by Strain and associates, most subjects $(68 \%)$ stated they understood the importance of changing their lifestyle and eating habits, however, only $37 \%$ accepted this as a way of treating type 2 diabetes mellitus [29].

The subjects in our research did not have satisfactory level of glycaemia. Satisfactory values $\mathrm{HbA} 1 \mathrm{c}<7.5 \%$ had
$61.6 \%$ of the subjects, but an average $\mathrm{HbA} 1 \mathrm{c}$ value of $7.2 \%$, and fasting glucose level in plasma of $7.8 \mathrm{mmol} / \mathrm{L}$ and a postprandial glucosee level in plasma of $9.3 \mathrm{mmol} / \mathrm{L}$ are above the target values of glycemic profile. It is similar in the rest of the world, so meta-analysis, involving 24 studies from 20 countries around the world showed poor glycemic control of $42.8 \%$, and the highest percentage of diabetics who reached the target glycaemia values were in Europe and North America [30]. In the surrounding countries (Serbia, Croatia, Bulgaria, Slovenia), less than $50 \%$ of patients have good glycemic control, and $\mathrm{HbA} 1 \mathrm{c}$ is routinely controlled in only $50 \%$ of type 2 diabetes mellitus patients [28].

\section{CONCLUSION}

Our study showed a significant impact of patient characteristics to poor glycemic control. Patients who consume alcohol, smokers, with unhealthy diet intake and elevated triglyceride and LDL cholesterol levels, were more likely to have poor glycemic control, unlike physically inactive patients, and patients with moderate or severe reduction of eGFR who were less likely to have poor glycemic control.

\section{ADVANTAGES AND LIMITATIONS}

The advantage of this study is that it reveals missing data for the studied population.

The limitation is that glycemic control is affected by different factors, not only by clinical characteristics and lifestyle habits explored in our research.

Data on the lifestyle habits were collected by selfassessment questionnaire, which includes the risk of underreporting or recall bias. However, this was taken into account in our data analysis.

\section{REFERENCES}

[1] Peyrot M, Bailey TS, Childs BP, Reach G. Strategies for implementing effective mealtime insulin therapy in type 2 diabetes. Curr Med Res Opinn 2018; 34:1153.

[2] International diabetes federation. Diabetes Atlas. 6th edition 2019.

[3] Tabak A, Herder C, Rathmann W, Brunner E, Kivimaki M. Prediabetes: a high risk state for developing diabetes. Lancet (2012) 379(9833):2279-90. doi:10.1016/S0140-6736(12)60283-9.

[4] How CB, Med M, Ming KE, Chin CY. Does religious affiliation influence glycaemic control in primary care patients with type 2 diabetes mellitus? Ment Health Fam Med 2011; 8: 21-28.

[5] Agardh E, Allebeck P, Hallqvist J, Moradi T, Sidorchuk A. Type 2 diabetes incidence and socio-economic position: a systematic review and meta-analysis. Int J Epidemiol 2011; 40: 804-18.

[6] Centers for Disease Control and Prevention National Diabetes Statistics Report: Estimates of Diabetes and Its Burden in the United States. U.S. Department of Health and Human Services 2014.

[7] Population health and health care in the Federation of Bosnia and Herzegovina in 2016. FBIH Institute of Public Health. Sarajevo, Available on:
oter http://www.fmoh.gov.ba/images/federalno_ministarstvo_zdravstva/pr eporucujemo/istrazivanja/Zdravstveno-stanje-stanovnistva-2016.pdf.

[8] Hrabac B, Spasojevic N. Non-communicable chronic diseases risk prevalence of family medicine patients in the Federation of Bosnia and Herzegovina. Mater SocioMed 2016; 28: 8-11.

[9] Ivanković A, Ravlija J, Skobić H, Vasilj I. Health status of population in Federation of Bosnia and Herzegovina in 15 years of transitional period. Coll Antropol. 2010; 34: 325-33.

[10] Zgibor, JC, Maloney, MA, Malmi, M, et al. Effectiveness of certified diabetes educators following pre-approved protocols to redesign 
diabetes care delivery in primary care: results of the REMEDIES 4D trial. Contemp Clin Trials. 2018; 64: 201-209.

[11] Bralić Lang V, Bergman Marković B, Vrdoljak D. The association of lifestyle and stress with poor glycemic control in patients with diabetes mellitus type 2: a Croatan nationwide primary care crosssectional study. Croat Med J 2015; 65: 357-65.

[12] Zheng D, Dou J, Liu G, Pan Y, Yan Y, Liu F et al. Association Between Triglyceride Level and Glycemic Control Among InsulinTreated Patients with Type 2 Diabetes.J Clin Endocrinol Metab. 2019;104(4):1211-1220.

[13] Zhao Q, Laukkanen JA, Li G. Body mass index is associated with type 2 diabetes mellitus in Chinese elderly. Clin Interv Aging 2017; 12: 745-52.

[14] Avramopoulos I, Moulis A, Nikas N. Glycaemic control, treatment satisfaction and quality of life in type 2 diabetes patients in Greece: The PANORAMA study Greek results. World J Diabetes 2015; 15: 208-16.

[15] Razi F, Forounzanfar K, Bandarian F, Nasli-Esfahani E. LDLcholesterol measurement in diabetic type 2 patients: a comparison between direct assay and popular equations. J Diabetes Metab Disord 2017; 16: 43-56.

[16] Mostafa SA, Coleman RL, Agbaje OF, Gray Am, Holman RR, Bethel MA. Simulating the impact of targeting lower systolic blood pressure and LDL-cholesterol levels on type 2 diabetes complication rates. J Diabetes Complications 2019; 33: 69-74.

[17] Pan A, Wang Y, Talaei M, Hu FB, Wu T. Relation of active, passive, and quitting smoking with incident type 2 diabetes: a systematic review and meta-analysis. Lancet Diabetes Endocrinol 2015; 3: 95867.

[18] Anan F, Takahashi N, Shinohara T, Nakagawa M, Masaki T, Katsuragi I i sur. Smoking is associated with insulin resistance and cardiovascular autonomic dysfunction in type 2 diabetic patients. Eur J Clin Invest 2006; 36: 459-65.

[19] Bermudez EA, Rifai N, Buring JE, Manson JE, Ridker PM. Relation between markers of systemic vascular inflammation and smoking in women. Am J Cardiol 2002; 89: 1117-9.

[20] Narkiewicz K, van de Borne PJ, Hausberg M, Cooley RL, Winniford $\mathrm{MD}$, Davison DE, et al. Cigarette smoking increases sympathetic outflow in humans. Circulation 1998; 98: 528-34.

[21] Okhuma T, Iwase M, Fuji H, Kaizu S, Ide H, Jodai T i sur. Dose- and time-dependent association of smoking and its cessation with glycemic control and insulin resistance in male patients with type 2 diabetes mellitus: the Fukuoka Diabetes Registry. Plus ONE. 2015;10.

[22] Lindström J, Hellström C, Molarius A, Simonsson B. Alcohol Consumption and Self-Rated Health among Older People in midSweden: Jim Lindström. Eur J Of Public Health 2017; ckx186.034, https://doi.org/10.1093/eurpub/ckx186.034.

[23] Syler JS, Bakris GL, Bonifacio E, Darsow T, Eckel RH, Groop L i sur. Differentiation of Diabetes by Pathophysiology, Natural History, and Prognosis. Diabetes 2017; 66: 241-55

[24] Mbanya JC, Aschner P, Gagliardino JJ at al. Factors Associated with Achievement of Glycemic Goal in Africa-Results from the International Diabetes Management Practices Study (IDMPS). Diabetes 2018;67:https://doi.org/10.2337/db18-2399-PUB.

[25] Snowling NJ, Hopkins WG. Effects of different modes of exercise training on glucose control and risk factors for complications in type 2 diabetic patients: a meta-analysis. Diabetes Care 2006; 29: 2518-27.

[26] Umpierre D, Ribeiro PA, Kramer CK i sur. Physical activity advice only or structured exercise training and association with HbAlc levels in type 2 diabetes: a systematic review and meta-analysis. JAMA 2011; 305: 1790-99.

[27] Yang Z, Scott CA, Mao C, Tang J, Farmer AJ. Resistance exercise versus aerobic exercise for type 2 diabetes: a systematic review and metaanalysis. Sports Med 2014; 44: 487-99.

[28] Cokolic M, Lalic NM, Micic D i sur. Patterns of diabetes care in Slovenia, Croatia, Serbia, Bulgaria and Romania: An observational, non-interventional, cross-sectional study. Wien Clin Wochenschr 2017; 129: 192-200.

[29] Straina W.D, Cosb, X, Hirst C, Venciod S, Mohand, V, Voko' f Z, Yabeg D, Blu“herh M, Palda'nius P.M. Time to do more: Addressing clinical inertia in the management of type 2 diabetes mellitus. Diabetes Res Clin Pract 2014; 105: 302-31.

[30] Khunti K, Ceriello A, Cos X, De Block C. Achievement of guideline targets for blood pressure, lipid, and glycaemic control in type 2 diabetes: A meta-analysis. Diabetes Res Clin Pract 2018; 137: 137-48. 